Article

\title{
Examining Relationships between Social Capital, Emotion Experience and Life Satisfaction for Sustainable Community
}

\author{
Tong Zou ${ }^{1, *(1)}$, Yikun $\mathrm{Su}^{2}$ and Yaowu Wang ${ }^{3}$ \\ 1 School of Management, Harbin Institute of Technology, Harbin 150001, China \\ 2 School of Civil Engineering, Northeast Forestry University, Harbin 150040, China; suyk@nefu.edu.cn \\ 3 Key Lab of Structures Dynamic Behavior and Control of the Ministry of Education; Key Lab of Smart \\ Prevention and Mitigation of Civil Engineering Disasters of the Ministry of Industry and Information \\ Technology, Harbin Institute of Technology, Harbin 150001, China; ywwang@hit.edu.cn \\ * Correspondence: zoutong0411@hit.edu.cn
}

Received: 11 May 2018; Accepted: 25 July 2018; Published: 27 July 2018

\begin{abstract}
As an important component of urban construction, the community sustainable construction is of great significance to the social development. Despite the importance of the social dimension of community sustainability, it has received relatively little attention when compared to the sustainability of environmental and economic dimensions. Based on the literature review, it is found that the social dimension of the sustainable community, such as residents' psychological feelings, social capital, has a strong effect on the sustainability of communities. This paper, therefore, conducts an empirical study on the mediating role of emotion experience on the associations between social capital and life satisfaction. Research on the relationship between them can help to generate synergies and strengthen the effect of promoting community sustainable development. A total of 229 complete responses from residents in China is used for data analysis. Results from the multiple linear regression analysis indicate that social capital has the significant positive effect on life satisfaction; the influence of social capital on life satisfaction is partly mediated by positive and negative affect, the social capital improves the life satisfaction through promoting positive affect, while it enhances the life satisfaction through restraining the negative affect. Based on the relationship between them, the relevant recommendations for the measures on the sustainable community can be proposed.
\end{abstract}

Keywords: sustainable community; social sustainability; social capital; emotion experience; life satisfaction

\section{Introduction}

Sustainable development has now been recognized as a priority by most countries [1]. About $65 \%$ of the world's population is expected to live in urban areas by the year 2025. As a regional society, the community is a place of people's social life in a certain geographical area and a place for belonging. Meanwhile, as a social space to meet the needs of residents, it is also a place need to proceed the community capacity building [2,3]. Thus, to realize the healthy and orderly development of the city, the first step is to conduct the community sustainable construction [4]. The economy and the environment construction activities have become household terms and always been the focus of community development [5]. However, with the improvement of living standards, people's requirements for the residential area have been continuously improved [6], non-materialistic lifestyle may improve well-being to some extent [7]. So, from the social perspective, social sustainability is an important part of urban sustainable development. 
In the literature, happiness is linked with sustainability [7]. Although social sustainability involves processes that promote well-being, it is often neglected in the sustainability debate [8]. Actually, the psychological perception and life satisfaction of residents are also of great significance in promoting community sustainability $[9,10]$. Residents' life satisfaction is the most direct and effective measure of the quality of life of residents. The study of residents' life satisfaction is conducive to the further improvement of residents' quality of life, which is conducive to the sustainable development of the community [11].

In the course of previous research, scholars and policymakers also have increasingly embraced the idea that the process of the community sustainability depends on increasing a community's available stock of social capital [12]. Meanwhile, based on the Community Capitals Frameworks (CCF) theory, communities can use community capitals to measure current resources and identify the potential for improvements [13]. Seven types of community capital that can be used as a gauge of how community resources are being used. Except for the capital associated with the environment and economic, social capital is an important item. To realize the community sustainability, it needs interactions between different parts [14]. Especially stresses the importance of widespread participation in the decision-making process $[15,16]$. Therefore, the impact of community social capital is proposed in this study.

Furthermore, according to the community psychology, any programs need to identify catalysts for action which can be targeted in order to effectively and efficiently meet their goals [17]. Residents' psychological feelings can be transformed into a kind of emotion experience and contribute to forming a kind of the sense of community and strengthening the relationship between the individual and the community, it will increase residents' trust and satisfaction with the community. Eventually, it has a strong effect on the sustainability of communities. Especially, the positive emotional perception, it will directly contribute to the improvement of residents' quality of life and the sustainable development of the community [18,19]. Accordingly, this study takes the emotion experience of residents as one of the research contents.

Through the above studies, it can be found that the research on residents' life satisfaction, community social capital stocks and residents' emotion experience all contribute to the improvement of community sustainability and also plays an important role in community management. Furthermore, with the deepening of research, it is found that the emotion experience of community residents and the stock of social capital owned by residents have an important role in the residents' life satisfaction [20,21]. Therefore, a question arises as to whether there is a relationship between social capital, emotion experience and life satisfaction and whether the relationship between them to generate synergies and strengthen the effect of promoting community sustainable development.

Based on the question mentioned above, this study takes the emotion experience as an intermediary variable, then discusses the mediating role of emotion experience on the associations between social capital and life satisfaction. To test the relationship between them, this study adopts an empirical research method. A questionnaire survey of 229 residents is used for the purpose of data analysis with SPSS and AMOS statistical software. Based on analyzing the relationship between the social capital, emotion experience and life satisfaction, this paper tries to illustrate a sense of social sustainability can have a catalytic effect on community sustainability construction by.

\section{Literature Review}

The list of necessities for the sustainable community given includes safe buildings, clean and comfortable living environment for residents, convenient community services and a variety of cultural life. Furthermore, environmental sustainability is also included, because climate change and the community environment will affect internal comfort [2,22]. Thus, in the modern society, debates about sustainable development seem to be mainly preoccupied with the economic and environmental dimensions of sustainability and the social aspect is neglected and the researchers and managers mostly focus on the development of physical spaces that enhances the well-being of individuals $[8,23]$. 
However, the social aspects of residents' psychological feelings, social capital have a strong effect on the sustainability of communities [24,25]. Findings like these lead to improving residents' life quality and contributing to more community sustainability [26].

\subsection{Life Satisfaction}

Life satisfaction is based on the people's emotional and cognitive evaluations. Individuals can evaluate their quality of life through subjective measures [27]. They are derived from the individual's own comprehensive psychological index to measure their quality of life. Previous research on the factors affecting life satisfaction focused on the influence of gender and age on life satisfaction [28]. Later, some scholars proposed that personal and family income, residential areas and social fairness perceptions, as well as individuals' perceptions of their own economic conditions, have a significant impact on residents' life satisfaction [29,30]. Accordingly, summing up past research in the academic field, we can conclude that the factors that affect the residents' life satisfaction mainly include objective factors such as family work environment, life events, socialization relationships and subjective factors such as values, self-esteem and cognition [31].

\subsection{Social Capital}

Improving social capital within community members is the building blocks of social sustainability [25]. It is considered that social capital is a collection of actual or potential resources. These resources can be closely related to a lasting network formed by institutionalized relationships that are commonly known or recognized by everyone [32]. This research takes the social capital of residents as the research perspective and divides social capital into two dimensions: structural social capital and cognitive social capital [33]. A further explanation of the two dimensions is that structural social capital refers to the external observable parts of social organizations, including community network and community participation. The cognitive dimension includes values, attitudes, norms and beliefs, as well as perceptions of support, reciprocity, sharing and trust among members of a specific population $[34,35]$.

\subsection{Emotion Experience}

Combining scholars' research on emotions, emotions are the attitudes and experiences of individuals towards objective things and they are the reactions of individuals to objective external things and the needs of subjective individuals themselves [36]. The emotion can be further classified into positive and negative affect [37]. Specifically, any emotions that can bring joyous experiences such as interest, excitement and enthusiasm are positive affect and emotions that can bring painful experiences such as fear, nervousness and shame are negative affect [38]. As an independent individual, residents have different emotion experience on different things. This is affected by many factors, including not only factors such as age, gender and other individual characteristics [39] but also affected by the objective environment [40].

\section{Research Hypotheses}

\subsection{Community Social Capital and Life Satisfaction}

Community social capital has a significant positive impact on life satisfaction. With the increase in individuals' own social capital stock, the higher their life satisfaction [41,42]. As one of the important factors affecting life satisfaction, many scholars have conducted extensive research on social capital [43-46], they consider that there is a strong and significant relationship between social capital and residents' life satisfaction [47]. Structural social capital can help to form a network connection consisted of community members by participating in community activities, so as to increase the richness of community life and thereby increase residents' life satisfaction. Previous studies have shown that increasing the frequency of social interactions, the degree of trust in society and the duration 
of participation in social activities can improve residents' life satisfaction and enhance happiness and well-being [8,48-51]. Furthermore, there is the general consensus that social support is an important factor in the quality of life and well-being, no matter in China or other countries [52-55], some studies even show that social support is necessary for well-being [56]. Specifically, numerous studies have provided evidence for the positive relationship between social support and life satisfaction $[57,58]$. At the same time, cognitive social capital can promote trust among community members and provide full reciprocity and communication, strengthen the feelings among community members and the sense of belonging of the community and thus improve the residents' life satisfaction. As an important part of social capital, trust is also the main factor affecting life satisfaction [21]. This study, therefore, attempts to investigate the impacts of social capital on life satisfaction, including structural social capital and cognitive social capital. The hypotheses can be advanced as follows:

Hypothesis 1a. The structural social capital of the community has a positive effect on the residents' life satisfaction.

Hypothesis 1b. The cognitive social capital of the community has a positive effect on the residents' life satisfaction.

\subsection{Community Social Capital and Emotion Experience}

There is a significant relationship between community social capital and emotion experience. The greater the stock of structural social capital has, the more frequent interactions among members in the community would exist. In the interactive process, the more members understand the basic information of the community (such as community norms and content), the more members are interested in the community. The more time you spend in the community, the more immersive and the more emotion you feel. Previous studies have shown that social interaction has an important influence on positive and negative affect. Social interaction has a positive influence on positive affect and can help individuals to maintain a positive emotional state. Social interaction has a negative impact on negative affect [59]. Many scholars have demonstrated that social support could affect the individual's emotional health [60-64], the other researchers further consider that social support is significantly positively correlated with positive affect and negatively related to negative affect [65]. It is believed that social capital, such as social support, can directly improve a positive experience. This experience will provide people with a better sense of satisfaction and a positive effect on subjective feelings [66]. The trust and mutual benefit in the cognitive social capital will increase the harmony of the community, form a happy and harmonious community atmosphere and increase the emotion experience of the community members. Therefore, this study attempts to investigate the impacts of social capital on emotion experience, social capital includes structural social capital and cognitive social capital and emotion experience includes positive affect and negative affect. And the hypotheses can be conducted as follows:

Hypothesis 2a. Structural social capital has a negative effect on residents' negative affect.

Hypothesis $\mathbf{2 b}$. Structural social capital has a positive effect on residents' positive affect.

Hypothesis 2c. Cognitive social capital has a negative effect on residents' negative affect.

Hypothesis 2d. Cognitive social capital has a positive effect on residents' positive affect.

\subsection{Emotion Experience and Life Satisfaction}

Emotion experience has an important impact on residents' life satisfaction. Emotion experience can increase residents' emotional awareness and sense of belonging to the community, thereby improving residents' life satisfaction. Some scholars show that life satisfaction, positive affect and 
negative affect are important dimensions for evaluating subjective well-being [67-69]. They believe that life satisfaction is a cognitive component of the evaluation of subjective well-being and that positive and negative affect are summarized as emotional factors [27]. And recently, many researchers have found that emotion experience would affect residents' life satisfaction [70-72], positive emotion can improve residents' life satisfaction and negative emotion could reduce residents' life satisfaction. However, life satisfaction cannot affect the individual's emotion experience [20,73]. Specifically, it is shown that positive emotions are significantly positively correlated with life satisfaction. Positive experiences that increase positive emotions have a positive effect on life satisfaction, negative emotions such as depression, tension and anxiety are significantly negatively correlated with life satisfaction, they can reduce individual's life satisfaction [74-77]. Accordingly, this study attempts to investigate the impact of emotion experience on residents' life satisfaction, emotion experience includes positive affect and negative affect. Thus, the hypotheses can be conducted as follows:

Hypothesis 3a. The residents' negative affect has a negative effect on the residents' life satisfaction.

Hypothesis $\mathbf{3 b}$. The residents' positive affect has a positive effect on the residents' life satisfaction.

\subsection{The Mediating Role of Emotion Experience}

In view of the above research on the relationship between community social capital, emotion experience and life satisfaction, it can be seen that the emotion experience may be a bridge and a link between community social capital and life satisfaction, indicating that the structural and the cognitive dimensions of social capital could promote positive emotions or suppresses the generation of negative emotions, thereby increasing residents' life satisfaction. Thus, this study also proposes the following hypotheses:

Hypothesis 4a. Negative affect plays an intermediary role in the relationship between structural social capital and life satisfaction.

Hypothesis $\mathbf{4 b}$. Negative affect plays an intermediary role in the relationship between cognitive social capital and life satisfaction.

Hypothesis 4c. Positive affect plays an intermediary role in the relationship between structural social capital and life satisfaction.

Hypothesis $4 \mathbf{d}$. Positive affect plays an intermediary role in the relationship between cognitive social capital and life satisfaction.

Based on the hypotheses between the three variables, this study constructs a hypothetical model between community social capital and life satisfaction under the role of emotion experience mediator (see Figure 1). 


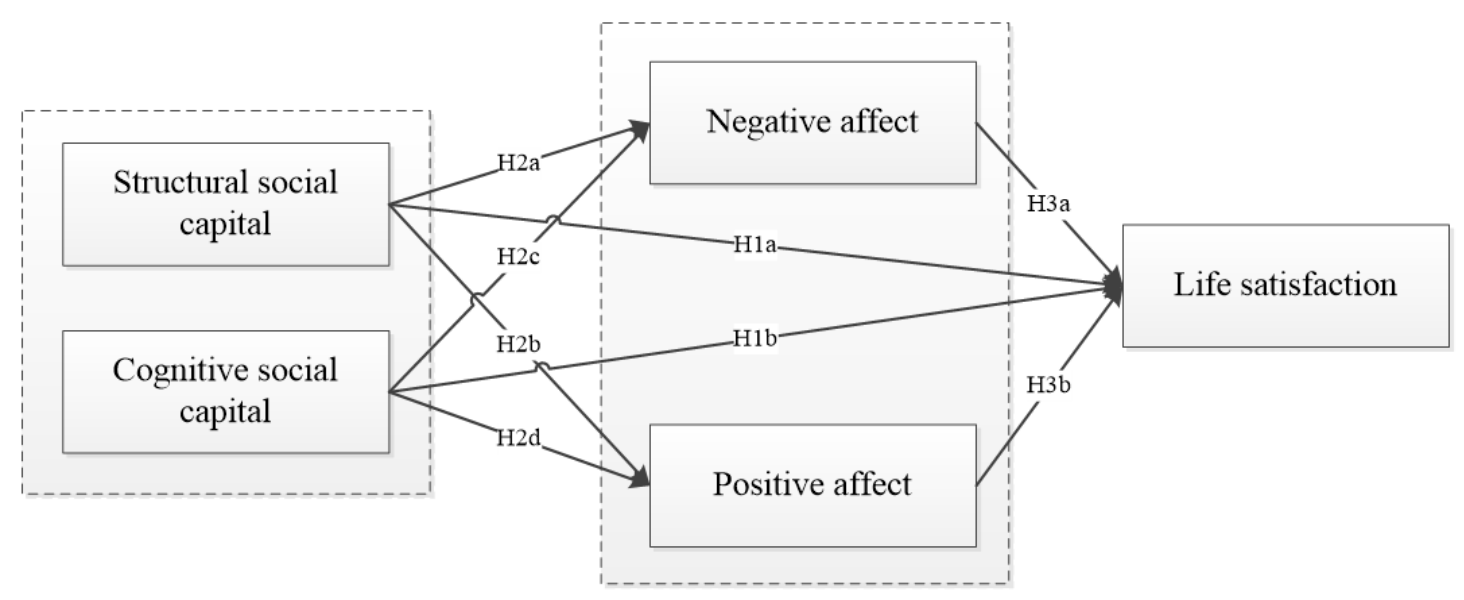

Figure 1. Hypothetical model.

\section{Methodology}

\subsection{Variable Measurement}

In this study, mature scales are used to measure the variables in the research model. The scales have been subject to extensive reliability and validity testing internationally and have previously been shown to exhibit acceptable psychometric properties among the Chinese population [58,78,79]. All measurement items are measured using the Likert 5-point method. Level 1-5 means strongly disagreed-strongly agree.

In order to measure the variable of life satisfaction, the life satisfaction scale (SWLS) proposed by Diener, Suh, Smith and Liang in1 995 is referred to [80]. This scale contains a total of 5 items, for example, my life is roughly in line with my ideal; if I can live again, there is almost nothing I want to change. For the consistency of the entire questionnaire, the answer is a Likert 5 scale (a higher degree of 1-5 indicates a higher level of life satisfaction).

Refer to the measurement of social capital, the simplified version of the Social Capital Measurement Tool (SASCAT) developed by Harpham et al. in 2002 is used in this study [34]. The community social capital is divided into two dimensions: structural social capital and cognitive social capital. Structural social capital includes six items such as measuring social interaction, social participation and social support. For example, the number of times you participated in your community's activities in the past six months. The measurement of cognitive social capital includes measuring five items such as social trust, community cohesion and community affiliation. For example, you think most people in your community can be trusted. The answer is a Likert 5 scale (1 means strongly disagree, 5 means strongly agree).

As for the measurement of emotion experience, the emotion experience scale (PANAS) proposed by Watson, Clark and Tellegen in 1988 is applied in this paper [81], it includes 20 items. 10 items measure positive affect (interested, excited, enthusiastic, etc.) and the other 10 items measure negative affect (fearful, nervous, shameful, etc.). The problem is the extent to which each emotion is experienced in the past month, using the Likert 5 scale (1 means nothing, the larger the number, the stronger the degree).

\subsection{Data Collection}

The questionnaire survey is a combination of paper questionnaires and online surveys. The research object analysis in this study is the community residents in China. Thus, the paper versions are released in five communities in Harbin. A self-addressed stamped envelope is attached for residents' easy return of the completed questionnaire by mail. An online survey is also provided 
on the website "Questionnaire Star". There is a little difference between the paper version and the online survey. One question is added into the online version, it is that" please specify the city you are".

Based on the contextual adjustment of scales (SWLS, SASCAT, PANAS), there are 42 questions in our questionnaire. Including four parts, demographic information, such as gender, age, education background, marital status, number of children, monthly income and questions about life satisfaction, social capital and emotion experience. And the survey is anonymous and the data collected will be used for research only.

A total of 250 questionnaires were distributed via on-site and 235 were recovered. The recovery rate was $94 \%$. Among them, invalid questionnaires such as omissions and blanks were excluded. Finally, 229 valid questionnaires were obtained and the effective recovery rate was $91.6 \%$. The following demographic information was collected from participants, as shown in Table 1. (Samples received from the online version were very little and could be ignored).

Table 1. Demographic Information $(N=229)$.

\begin{tabular}{|c|c|c|c|c|c|}
\hline & Personal Particulars & Rate/\% & & Personal Particulars & Rate $/ \%$ \\
\hline \multirow[b]{2}{*}{ Gender } & Male & 43.7 & \multirow{4}{*}{ Marital status } & Married & 15.3 \\
\hline & Female & 56.3 & & Single & 83.3 \\
\hline \multirow{5}{*}{ Age } & $18-30$ & 80.0 & & Divorced & 0.3 \\
\hline & $31-40$ & 4.8 & & Widowed & 1.1 \\
\hline & $41-50$ & 7.4 & \multirow{3}{*}{$\begin{array}{l}\text { Number of } \\
\text { children }\end{array}$} & 0 & 84.3 \\
\hline & $51-60$ & 5.2 & & 1 & 9.2 \\
\hline & $\geq 60$ & 2.6 & & $\geq 2$ & 6.5 \\
\hline \multirow{5}{*}{$\begin{array}{l}\text { Education } \\
\text { background }\end{array}$} & Primary school and below & 2.2 & \multirow{5}{*}{$\begin{array}{c}\text { Monthly } \\
\text { income/yuan }\end{array}$} & $\leq 1000$ & 35.8 \\
\hline & Junior high school & 7.7 & & $1000-2000$ & 13.1 \\
\hline & $\begin{array}{c}\text { Senior high school/Specialized } \\
\text { Secondary Schools }\end{array}$ & 3.5 & & 2000-4000 & 36.7 \\
\hline & Undergraduate/Specialty & 52.0 & & $4000-8000$ & 12.2 \\
\hline & Graduate student and above & 34.5 & & $\geq 8000$ & 2.2 \\
\hline
\end{tabular}

\subsection{Reliability and Validity of the Scale}

In this study, AMOS17.0 and SPSS17.0 data statistics software is used to test the reliability and validity of the measurement scale through confirmatory factor analysis and exploratory factor analysis. This study uses Cronbach $\alpha$ to analyze the reliability of the measurement scale. It is generally believed that the Cronbach $\alpha$ coefficient greater than 0.70 indicates that the questionnaire has high reliability; At the same time, the factor load is used to illustrate the validity of the survey questionnaire. It is generally believed that the factor loading should be between $0.45-0.95$, thereby the data validity is good. The KMO test is used to ensure that the data used in this study can be used to conduct the factor analysis and the minimum standard for KMO is generally considered to be 0.5 . As shown in Table 2, the Cronbach $\alpha$ coefficients of all indexes are all above 0.7 , indicating that the reliability of each scale is good and it can be seen that the factor loads of all variables are significant and the value of KMO is also above 0.5 . Therefore, all indicators achieve the standard, indicating that the validity of the questionnaire is good. 
Table 2. Reliability and Validity of the Scale.

\begin{tabular}{|c|c|c|c|c|c|c|c|c|c|c|c|c|c|c|c|}
\hline \multicolumn{4}{|c|}{ Social Capital } & \multicolumn{8}{|c|}{ Emotion Experience } & \multicolumn{4}{|c|}{ Life Satisfaction } \\
\hline Item & FL & $\alpha$ & KMO & Item & FL & $\alpha$ & KMO & Item & FL & $\alpha$ & KMO & Item & FL & $\alpha$ & $\mathrm{KMO}$ \\
\hline SS1 & 0.596 & & & PA1 & 0.610 & & & NA1 & 0.616 & & & LS1 & 0.735 & & \\
\hline SS2 & 0.658 & & & PA2 & 0.542 & & & NA2 & 0.611 & & & LS2 & 0.682 & & \\
\hline SS3 & 0.640 & & & PA3 & 0.594 & & & NA3 & 0.601 & & & LS3 & 0.622 & 0.807 & 0.824 \\
\hline SS4 & 0.646 & 0.808 & 0.857 & PA4 & 0.556 & & & NA4 & 0.694 & & & LS4 & 0.626 & & \\
\hline SS5 & 0.667 & & & PA5 & 0.581 & & & NA5 & 0.715 & & & LS5 & 0.708 & & \\
\hline SS6 & 0.658 & & & PA6 & 0.517 & 0.831 & 0.884 & NA6 & 0.695 & 0.880 & 0.900 & & & & \\
\hline CS1 & 0.559 & & & PA7 & 0.600 & & & NA7 & 0.633 & & & & & & \\
\hline CS2 & 0.600 & & & PA8 & 0.563 & & & NA8 & 0.620 & & & & & & \\
\hline CS3 & 0.580 & 0.710 & 0.773 & PA9 & 0.571 & & & NA9 & 0.653 & & & & & & \\
\hline CS4 & 0.502 & & & PA10 & 0.637 & & & NA10 & 0.673 & & & & & & \\
\hline CS5 & 0.630 & & & & & & & & & & & & & & \\
\hline
\end{tabular}

Note. FL: factor loading; $\alpha$ : Cronbach $\alpha$; SS: structural social capital, including 6 items such as social participation, social support and social interaction; CS: cognitive social capital, including 5 items such as social trust, community cohesion and a sense of belonging; PA: positive affect, including 10 items such as excited and enthusiastic; NA: negative affect, including 10 items such as sad, scared; LS: life satisfaction, including 5 items.

In order to test the difference between structural social capital, cognitive social capital, positive affect, negative affect and life satisfaction, this study uses AMOS 17.0 software to test the discriminant validity of five variables through confirmatory factor analysis. The confirmatory factor analysis of the five-factor model, four-factor model, three-factor model and single factor model are conducted separately. The matching of the various indicators obtained is used to illustrate the fitness of the structural model. It can be seen from Table 3, the five-factor model fits the data best $\left(\chi^{2} / \mathrm{d} f=1.456\right.$, $\mathrm{IFI}=0.906, \mathrm{CFI}=0.905, \mathrm{TLI}=0.897, \mathrm{RMSEA}=0.045)$ and it is superior to the four-factor, three-factor and single-factor model, indicating that the five variables in this study have good discriminant validity and illustrate that the structural model of this study has a good fit.

Table 3. Model fit.

\begin{tabular}{cccccccc}
\hline Model & $\chi^{2}$ & $\mathrm{~d} f$ & $\chi^{2} / \mathrm{d} f$ & IFI & CFI & TLI & RMSEA \\
\hline $\begin{array}{c}\text { Five-variable model } \\
\text { (SS, CS, PA, NA, LS) }\end{array}$ & 853.236 & 586 & 1.456 & 0.906 & 0.905 & 0.897 & 0.045 \\
\hline $\begin{array}{c}\text { Four-variable model } \\
\text { (SS, CS, PA + NA, LS) }\end{array}$ & 1036.829 & 589 & 1.760 & 0.842 & 0.840 & 0.829 & 0.058 \\
\hline $\begin{array}{c}\text { Three-variable model } \\
\text { (SS + CS, PA + NA, LS) }\end{array}$ & 1166.228 & 591 & 1.973 & 0.715 & 0.710 & 0.691 & 0.065 \\
\hline $\begin{array}{c}\text { Two-variable model } \\
(\text { SS + CS + PA + NA + LS) }\end{array}$ & 1196.903 & 594 & 2.015 & 0.787 & 0.785 & 0.772 & 0.067 \\
\hline
\end{tabular}

Note. SS: structural social capital; CS: cognitive social capital; PA: positive affect; NA: negative affect; LS: life satisfaction.

\section{Results}

\subsection{Descriptive Statistics and Correlation Analysis}

To test the validity of the research hypotheses, a preliminary test is performed on the correlation analysis between the variables. The mean, standard deviation of each variable and the correlation coefficients and significance between variables can be calculated by the SPSS 17.0 statistical software (see Table 4). The correlation analysis results show that there are significant correlations between different variables $(p<0.01)$. The correlations between structural social capital, cognitive social capital and life satisfaction $(r=0.448, r=0.432, p<0.01)$, between structural social capital, cognitive social capital and positive affect $(r=0.638, r=0.633, p<0.01)$, between structural social capital, cognitive social capital and negative affect $(r=-0.650, r=-0.550, p<0.01)$, between positive affect, negative affect and life satisfaction $(r=0.456, r=-0.508, p<0.01)$ are all significantly related at the 0.01 level. It could be initially demonstrated that there is a correlation between any of the social capital, emotion 
experience and life satisfaction. Therefore, the initial test of the hypotheses is passed. At the same time, the correlation coefficients between any two variables are less than 0.7 , indicating that there is no "excessively same problem" and the discriminant validity between variables is good.

Table 4. Descriptive statistics and correlation analysis.

\begin{tabular}{cccccccc}
\hline & M & SD & SS & CS & PA & NA & LS \\
\hline SS & 2.6317 & 0.53870 & 1 & & & & \\
CS & 2.9886 & 0.52487 & $0.528^{* *}$ & 1 & & & \\
PA & 2.7563 & 0.47712 & $0.638^{* *}$ & $0.633^{* *}$ & 1 & & \\
NA & 2.5376 & 0.55739 & $-0.650^{* *}$ & $-0.550^{* *}$ & $-0.576^{* *}$ & 1 & \\
LS & 2.9869 & 0.65722 & $0.448^{* *}$ & $0.432^{* *}$ & $0.456^{* *}$ & $-0.508^{* *}$ & 1 \\
\hline
\end{tabular}

Note. ${ }^{* *}$ indicates $p<0.01$; SS: structural social capital; CS: cognitive social capital; PA: positive affect; NA: negative affect; LS: life satisfaction.

\subsection{Verification Results of the Research Hypothesis}

\subsubsection{Direct Influences between Variables}

The final hypotheses test results of this study are shown in Table 5. As shown in Table 5, the benchmark model 5 shows the influences of demographic variables such as gender and age on residents' life satisfaction, it is found that personal income has a significant positive effect on residents' life satisfaction. Model 6 controls demographic variables. Structural social capital and cognitive social capital have significant positive effects on residents' life satisfaction. The hypothesis 1a and hypothesis $1 \mathrm{~b}$, therefore, are verified. Furthermore, according to model 9 and model 10, both the positive affect and the negative affect of emotion experience have significant impacts on residents' life satisfaction. Positive affect has a significant positive effect on life satisfaction. Negative affect has a significant negative effect on life satisfaction, the Hypotheses $3 a$ and $3 b$ are verified. In model 2, demographic variables are controlled and structural social capital and cognitive social capital have significant positive effects on positive affect and $2 \mathrm{~b}$ and $2 \mathrm{~d}$ are validated. In Model 4 , structural social capital and cognitive social capital have negative effects on negative affect and $2 \mathrm{a}$ and $2 \mathrm{c}$ are verified.

\subsubsection{The Mediating Role of Emotion Experience}

To test the mediating role of emotion experience between social capital and life satisfaction, a three-step intermediate regression analysis is used. According to Models 4 and 6, it is showed that the structural dimension and cognitive dimension of social capital are significantly negatively related to the negative affect and are significantly positively related to life satisfaction. When the negative affect is added to model 6 , it is the model 8 . The results show that the significance or the correlation coefficients of the structural social capital and cognitive social capital have significant decrease, while the regression coefficient of negative affect is $-0.374(p<0.01)$, which is significantly correlated. Therefore, the negative affect plays partial intermediary roles between structural social capital, cognitive social capital and life satisfaction. Social capital would improve residents' life satisfaction by suppressing negative affect. Hypothesis $4 \mathrm{a}$ and hypothesis $4 \mathrm{~b}$ are obtained partial verification. Meanwhile, according to Model 2 and Model 6, it is illustrated that the structural dimension and cognitive dimension of social capital have significant positive effects on positive affect and life satisfaction. the positive affect variable is added to model 6, it is the Model 7. The results show that the structural social capital significantly reduces the life satisfaction of the residents and the significance between the cognitive capital and life satisfaction also decrease and the positive affect has a regression coefficient of $0.279(p<0.05)$, significantly related. Accordingly, positive affect plays partial intermediary roles between structural social capital, cognitive social capital and life satisfaction. Social capital can improve residents' life satisfaction by promoting positive affect. Hypotheses $4 \mathrm{c}$ and $4 \mathrm{~d}$ are obtained partial verification. 
Table 5. Regression analysis results $(N=229)$.

\begin{tabular}{|c|c|c|c|c|c|c|c|c|c|c|c|}
\hline & \multirow{3}{*}{ Variable } & \multicolumn{4}{|c|}{ Emotion Experience } & \multirow{2}{*}{\multicolumn{6}{|c|}{ Life Satisfaction }} \\
\hline & & \multicolumn{2}{|c|}{ Positive Affect } & \multicolumn{2}{|c|}{ Negative Affect } & & & & & & \\
\hline & & 1 & 2 & 3 & 4 & 5 & 6 & 7 & 8 & 9 & 10 \\
\hline \multirow{5}{*}{$\begin{array}{c}\text { Control } \\
\text { variable }\end{array}$} & Gender & -0.024 & -0.049 & -0.052 & -0.024 & 0.017 & -0.007 & 0.007 & -0.016 & 0.033 & -0.015 \\
\hline & Age & $-0.260^{* *}$ & $-0.135 *$ & $0.248^{*}$ & 0.107 & -0.070 & 0.051 & 0.088 & 0.091 & 0.096 & 0.082 \\
\hline & Marital status & -0.058 & -0.002 & 0.120 & 0.051 & 0.046 & 0.100 & 0.101 & 0.120 & 0.083 & 0.119 \\
\hline & Education background & -0.073 & -0.076 & -0.027 & -0.015 & -0.067 & -0.072 & -0.051 & -0.078 & -0.021 & -0.084 \\
\hline & Number of children & $0.389 *$ & 0.142 & $-0.545^{* *}$ & -0.271 & -0.072 & -0.310 & -0.350 & $-0.411^{*}$ & -0.319 & $-0.406^{*}$ \\
\hline \multirow{8}{*}{$\begin{array}{l}\text { Research } \\
\text { variables }\end{array}$} & SS & & $0.371^{* *}$ & & $-0.493^{* *}$ & & $0.365^{* *}$ & $0.262 * *$ & $0.181 *$ & & \\
\hline & CS & & $0.366^{* *}$ & & $-0.290^{* *}$ & & $0.343^{* *}$ & $0.241 *$ & $0.234^{* *}$ & & \\
\hline & PA & & & & & & & 0.279 * & & $0.636^{* *}$ & \\
\hline & NA & & & & & & & & $-0.374^{* *}$ & & $-0.612^{* *}$ \\
\hline & $\mathrm{R}^{2}$ & 0.052 & $0.549 * *$ & $0.092 * *$ & $0.513^{* *}$ & 0.035 & $0.276^{* *}$ & $0.295^{* *}$ & $0.325^{* *}$ & $0.237^{* *}$ & $0.279 * *$ \\
\hline & $\mathrm{F}$ & 2.018 & $33.487^{* *}$ & $3.764^{* *}$ & $29.008^{* *}$ & 1.331 & $10.505^{* *}$ & $10.177^{* *}$ & $11.747^{* *}$ & $9.808^{* *}$ & $12.227^{* *}$ \\
\hline & $\Delta \mathrm{R}^{2}$ & 0.052 & $0.497^{* *}$ & $0.092 * *$ & $0.421^{* *}$ & 0.035 & $0.242^{* *}$ & $0.018^{* *}$ & $0.049^{* *}$ & $0.202^{* *}$ & $0.244^{* *}$ \\
\hline & $\Delta \mathrm{F}$ & 2.018 & $121.328^{* *}$ & $3.764^{* *}$ & $95.161 * *$ & 1.331 & $36.742 * *$ & $5.745^{* *}$ & $15.936^{* *}$ & $58.600^{* *}$ & $74.941^{* *}$ \\
\hline
\end{tabular}

Note. ${ }^{* *}$ indicates $p<0.01$; ${ }^{*}$ indicates $p<0.05$; SS: structural social capital; CS: cognitive social capital; PA: positive affect; NA: negative affect; LS: life satisfaction. 


\section{Discussions}

The main purpose of this study is to research the relationship between the different variables in the context of the Chinese community, including social capital, residents' emotion experience and residents' life satisfaction. Based on the certification of the relationship between them, combined with the review of the relationship and community sustainability construction respectively, discussion the contribution of generating synergies and strengthening the effect. The results of this study validate all proposed research hypotheses. And provide the inspiration to researchers and practitioners.

\subsection{Community Social Capital Has a Positive Effect on Life Satisfaction}

This result is consistent with previous studies. This study divides social capital into two dimensions: structural social capital and cognitive social capital and focused on the relationship between the social capital and residents' life satisfaction. The results show that there are significant positive effects of structural social capital and cognitive social capital on life satisfaction. Structural social capital such as the residents' social participation, social interaction and acquired social support can increase residents' happiness and enhance their satisfaction [47]. Similarly, residents' trust in others and the communities, the belonging sense to the communities and the cohesiveness can also increase their life satisfaction [21]. Therefore, for community managers, in the process of community management and community activities, it can be analyzed from the perspective of sociology, improving the community sustainability by increasing the stock of the community's social capital. Meanwhile, the way of these will also enhance residents' trust in the community and improve residents' life satisfaction, finally, achieve the sustainability of community development.

\subsection{Negative Affect Has Partial Mediation in the Relationship between Community Social Capital and Life Satisfaction}

According to the research findings, when community residents conduct more social interactions, more social participation, obtain adequate social support and give residents more sense of security and belonging, the less negative effects of community residents would have, thereby it would have a more effective influence to avoid a negative effect between social capital and life satisfaction. There is one result proposed by this study that requires us to pay special attention. The negative affect has a more significant mediating effect on structural social capital and life satisfaction. It means that the individual social participation and social interaction are more conducive to suppressing negative affect, thereby improving residents' life satisfaction. Therefore, in this process, the emphasis needs to focus on increasing the management of community-structural social capital, increasing the participation in the community activity and interacting with other residents, thereby suppressing negative affect and achieving the purpose of enhancing residents' happiness perception and improving residents' life satisfaction.

\subsection{Positive Affect Has Partial Mediation in the Relationship between Community Social Capital and Life Satisfaction}

Similar to the results of the negative affect, residents have more stocks of social capital, which can promote the positive affect, thus enhancing positive influence on the association between social capital and life satisfaction. However, different from the negative affect, the positive affect has more obvious mediating effects on cognitive social capital and life satisfaction. In other words, the cohesion, sense of belonging and trust supported by the community are more likely to promote the residents' positive emotions and thus increase their life satisfaction [82]. Therefore, for managers, it is necessary to actively cultivate the relationship between citizens, help to build political consensus and will, strengthen neighborhood relations, improve inter-group relationships and create good-neighbor relationships that will help to meet daily needs. Obviously, the focus is to promote the perception of positive affect by increasing the stock of cognitive-based social capital, thereby bringing better life satisfaction to residents and the community sustainability. 


\section{Conclusions}

This paper tries to illustrate that a sense of social sustainability can have a catalytic effect on community sustainability construction by analyzing the relationship between social capital, emotion experience and life satisfaction. Communities are systems that have inflows and outflows, ups and downs, progression and regression. It means that a community needs interactions between different parts, including the environmental, economic and social parts. Based on the sociological perspective of community sustainable development, this study conducts the relationship between community social capital stock, emotion experience and residents' life satisfaction. Through empirical research method, a questionnaire survey is conducted on 229 selected residents. The results show that the community's structural social capital and cognitive social capital have a positive impact on residents' life satisfaction, the community's structural social capital and cognitive social capital stock have positive impacts on the residents' positive affect, however, they have negative impacts on residents' negative affect. At the same time, positive affect and negative affect have partial mediating effects on the relationship between community social capital stock and residents' life satisfaction, all the hypotheses of this study have been verified. The review of relevant literature and the confirmation of the hypothetical results are of great significance to managers. They can not only promote the sustainable construction of the community through the improvement of social capital, emotion experience or life satisfaction. Furthermore, research on the relationship between them can help to generate synergies and strengthen the effect of promoting community sustainable development.

However, this study also has some limitations: (A) Because of the limitation of the demographic and samples, we did not compare the relationship of social capital, emotion experience and life satisfaction between the rural and urban residents. Chinese rural community has the different background with urban community. The results may be different. This is an important research point. (B) This paper did not conduct the research on the relationship between community sustainability and social capital, emotion experience or life satisfaction, just provided the opinion based on the literature review. We can test independent predictors between them in the future. (C) This study adopted a cross-sectional study in the design. When social capital influences life satisfaction through emotion experience, the effect of the mediating variable is a long process and has a certain time effect. If we can measure the causality between social capital and residents' life satisfaction at different times, it may be more significant. Accordingly, in future studies, research and design should adopt a longitudinal study to increase the causal relationship between variables and the accuracy.

Author Contributions: Z.T. and W.Y. wrote the paper; S.Y. designed and collected the questionnaire.

Funding: This research was supported by the National Key R\&D Program of China (No. 2016YFC0701600).

Acknowledgments: Sincerely thank some experts who provide some technical guidance for this research.

Conflicts of Interest: The authors declare no conflict of interest.

\section{References}

1. Dempsey, N.; Bramley, G.; Power, S.; Brown, C. The social dimension of sustainable development: Defining urban social sustainability. Sustain. Dev. 2011, 19, 289-300. [CrossRef]

2. Tönnies, F. Community and Society; The Urban Sociology Reader; Harper \& Row: New York, NY, USA, 1887.

3. Chaskin, R.; Brown, P.; Venkatesh, S.; Vidal, A. Building Community Capacity; Aldine de Gruyter: New York, NY, USA, 2001.

4. Friedman, A. Sustainable and Resource—Efficient Homes and Communities; Multidisciplinary Digital Publishing Institute: Basel, Switzerland, 2017.

5. Zhang, D.W.; Yan, M.C. Community work stations: An incremental fix of the community construction project in China. Commun. Dev. J. 2013, 49, 143-158. [CrossRef]

6. Billings, J.R. Community development: A critical review of approaches to evaluation. J. Adv. Nurs. 2000, 31, 472-480. [CrossRef] [PubMed] 
7. Grinde, B.; Nes, R.B.; MacDonald, I.F.; Wilson, D.S. Quality of Life in Intentional Communities. Soc. Indic. Res. 2018, 137, 625-640. [CrossRef]

8. Munzel, A.; Meyer-Waarden, L.; Galan, J.-P. The social side of sustainability: Well-being as a driver and an outcome of social relationships and interactions on social networking sites. Technol. Forecast. Soc. Chang. 2018, 130, 14-27. [CrossRef]

9. Ross, C.E.; Reynolds, J.R.; Geis, K.J. The contingent meaning of neighborhood stability for residents' psychological well-being. Am. Sociol. Rev. 2000, 65, 581-597. [CrossRef]

10. Weidemann, S.; Anderson, J.R.; Butterfield, D.I.; O'Donnell, P.M. Residents' perceptions of satisfaction and safety: A basis for change in multifamily housing. Environ. Behav. 1982, 14, 695-724. [CrossRef]

11. Sirgy, M.J.; Rahtz, D.R.; Cicic, M.; Underwood, R. A method for assessing residents' satisfaction with community-based services: A quality-of-life perspective. Soc. Indic. Res. 2000, 49, 279-316. [CrossRef]

12. Flora, J.L. Social capital and communities of place. Rural Sociol. 1998, 63, 481-506. [CrossRef]

13. Emery, M.; Flora, C. Spiraling-up: Mapping community transformation with community capitals framework. Commun. Dev. 2006, 37, 19-35. [CrossRef]

14. Jacobs, C. Measuring Success in Communities: The Community Capitals Framework; SDSU Extension Extra Archives; SDSU: San Diego, CA, USA, 2011; p. 517.

15. Bridger, J.C.; Luloff, A.E. Building the sustainable community: Is social capital the answer? Sociol. Inquiry 2001, 71, 458-472. [CrossRef]

16. Bolino, M.C.; Turnley, W.H.; Bloodgood, J.M. Citizenship behavior and the creation of social capital in organizations. Acad. Manag. Rev. 2002, 27, 505-522. [CrossRef]

17. Chavis, D.M.; Wandersman, A. Sense of community in the urban environment: A catalyst for participation and community development. Am. J. Commun. Psychol. 1990, 18, 55-81. [CrossRef]

18. Chou, C.Y.; Sawang, S. Virtual community, purchasing behaviour, and emotional well-being. Australas. Mark. J. 2015, 23, 207-217. [CrossRef]

19. Abbey, A.; Andrews, F.M. Modeling the psychological determinants of life quality. Soc. Indic. Res. 1985, 16, 1-34. [CrossRef]

20. Ya, L. The Relation Between Neuroticism and Life Satisfaction: The Chain Mediating Effects of Affect and Self-Esteem. Psychol. Sci. 2012, 35, 1254-1260.

21. Leung, A.; Kier, C.; Fung, T.; Fung, L.; Sproule, R. Searching for happiness: The importance of social capital. J. Happiness Stud. 2011, 12, 443-462. [CrossRef]

22. Bridger, J.C.; Luloff, A.E. Toward an interactional approach to sustainable community development. J. Rural Stud. 1999, 15, 377-387. [CrossRef]

23. Åhman, H. Social sustainability-society at the intersection of development and maintenance. Local Environ. 2013, 18, 1153-1166. [CrossRef]

24. Rogge, N.; Theesfeld, I.; Strassner, C. Social Sustainability through Social Interaction-A National Survey on Community Gardens in Germany. Sustainability 2018, 10, 1085. [CrossRef]

25. Markle, E.A.; Rodgers, R.; Sanchez, W.; Ballou, M. Social support in the cohousing model of community: A mixed-methods analysis. Commun. Dev. 2015, 46, 616-631. [CrossRef]

26. Yu, B.; Che, S.; Xie, C.; Tian, S. Understanding Shanghai Residents' Perception of Leisure Impact and Experience Satisfaction of Urban Community Parks: An Integrated and IPA Method. Sustainability 2018, 10, 1067. [CrossRef]

27. Diener, E.; Oishi, S.; Lucas, R.E. Personality, culture, and subjective well-being: Emotional and cognitive evaluations of life. Annu. Rev. Psychol. 2003, 54, 403-425. [CrossRef] [PubMed]

28. Blanchflower, D.G.; Oswald, A.J. Well-being over time in Britain and the USA. J. Public Econ. 2004, 88, 1359-1386. [CrossRef]

29. Brockmann, H.; Delhey, J.; Welzel, C.; Yuan, H. The China puzzle: Falling happiness in a rising economy. J. Happiness Stud. 2009, 10, 387-405. [CrossRef]

30. Ma, J.; Dong, G.; Chen, Y.; Zhang, W. Does satisfactory neighbourhood environment lead to a satisfying life? An investigation of the association between neighbourhood environment and life satisfaction in Beijing. Cities 2018, 74, 229-239. [CrossRef]

31. Du, P.; Wood, A.; Ditchman, N.; Stephens, B. Life Satisfaction of Downtown High-Rise vs. Suburban Low-Rise Living: A Chicago Case Study. Sustainability 2017, 9, 1052. [CrossRef] 
32. Richardson, J.G. Handbook of Theory and Research for the Sociology of Education; Greenwood Publishing Group: Westport, CT, USA, 1986.

33. Uphoff, N. Understanding Social Capital: Learning from the Analysis and Experience of Participation. Social Capital: A Multifaceted Perspective; Cornell University Press: Ithaca, NY, USA, 2000; pp. 215-249.

34. Harpham, T.; Grant, E.; Thomas, E. Measuring social capital within health surveys: Key issues. Health Policy Plan. 2002, 17, 106-111. [CrossRef] [PubMed]

35. Liu, J.; Qu, H.; Huang, D.; Chen, G.; Yue, X.; Zhao, X.; Liang, Z. The role of social capital in encouraging residents' pro-environmental behaviors in community-based ecotourism. Tour. Manag. 2014, 41, 190-201. [CrossRef]

36. Liu, H. The Study of Students' Perceived Social Support and Negative Emotion. Sci. Soc. Psychol. 2012, 27, 39-42.

37. Diener, E.; Emmons, R.A. The independence of positive and negative affect. J. Personal. Soc. Psychol. 1984, 47, 1105-1117. [CrossRef]

38. Crawford, J.R.; Henry, J.D. The Positive and Negative Affect Schedule (PANAS): Construct validity, measurement properties and normative data in a large non-clinical sample. Br. J. Clin. Psychol. 2004, 43, 245-265. [CrossRef] [PubMed]

39. Charles, S.T.; Reynolds, C.A.; Gatz, M. Age-related differences and change in positive and negative affect over 23 years. J. Personal. Soc. Psychol. 2001, 80, 136-151. [CrossRef]

40. Watson, D. Intraindividual and interindividual analyses of positive and negative affect: Their relation to health complaints, perceived stress, and daily activities. J. Personal. Soc. Psychol. 1988, 54, 1020-1030. [CrossRef]

41. Jinlong, Y. An Empirical Analysis of the Impact of Village Community Social Capital and Family Affinity on Senior Citizens' Life Satisfaction. Stat. Decis. 2013, 15, 101-104. [CrossRef]

42. Inaba, Y.; Wada, Y.; Ichida, Y.; Nishikawa, M. Which part of community social capital is related to life satisfaction and self-rated health? A multilevel analysis based on a nationwide mail survey in Japan. Soc. Sci. Med. 2015, 142, 169-182. [CrossRef] [PubMed]

43. Coleman, J.S. Social capital in the creation of human capital. Am. J. Sociol. 1988, 94, S95-S120. [CrossRef]

44. Helliwell, J.F. How's life? Combining individual and national variables to explain subjective well-being. Econ. Model. 2003, 20, 331-360. [CrossRef]

45. Tokuda, Y.; Fujii, S.; Inoguchi, T. Individual and country-level effects of social trust on happiness: The Asia barometer survey. J. Appl. Soc. Psychol. 2010, 40, 2574-2593. [CrossRef]

46. Elgar, F.J.; Davis, C.G.; Wohl, M.J.; Trites, S.J.; Zelenski, J.M.; Martin, M.S. Social capital, health and life satisfaction in 50 countries. Health Place 2011, 17, 1044-1053. [CrossRef] [PubMed]

47. Ateca-Amestoy, V.; Aguilar, A.C.; Moro-Egido, A.I. Social interactions and life satisfaction: Evidence from Latin America. J. Happiness Stud. 2014, 15, 527-554. [CrossRef]

48. Zhiyang, H. Social Capital and Farmers' Life Quality. J. Huaqiao University (Hum. Soc. Sci.) 2010, 118-124.

49. Dröes, R.; Chattat, R.; Diaz, A.; Gove, D.; Graff, M.; Murphy, K.; Verbeek, H.; Vernooij-Dassen, M.; Clare, L.; Johannessen, A. Social health and dementia: A European consensus on the operationalization of the concept and directions for research and practice. Aging Mental Health 2017, 21, 4-17. [CrossRef] [PubMed]

50. Thomas, J.E.; O'Connell, B.; Gaskin, C.J. Residents' perceptions and experiences of social interaction and participation in leisure activities in residential aged care. Contemp. Nurse 2013, 45, 244-254. [CrossRef] [PubMed]

51. Meeks, S.; Van Haitsma, K.; Kostiwa, I.; Murrell, S.A. Positivity and well-being among community-residing elders and nursing home residents: What is the optimal affect balance? J. Gerontol. Ser. B Psychol. Sci. Soc. Sci. 2012, 67, 460-467. [CrossRef] [PubMed]

52. Kahn, J.H.; Hessling, R.M.; Russell, D.W. Social support, health, and well-being among the elderly: What is the role of negative affectivity? Personal. Indiv. Differ. 2003, 35, 5-17. [CrossRef]

53. Liu, H.; Li, S.; Xiao, Q.; Feldman, M. Social support and psychological well-being under social change in urban and rural China. Soc. Indic. Res. 2014, 119, 979-996. [CrossRef]

54. Steiner, A.; Raube, K.; Stuck, A.E.; Aronow, H.U.; Draper, D.; Rubenstein, L.Z.; Beck, J.C. Measuring Psychosocial Aspects of Weil-Being in Older Community Residents: Performance of Four Short Scales. Gerontologist 1996, 36, 54-62. [CrossRef] [PubMed] 
55. Shields, M.A.; Price, S.W. Exploring the economic and social determinants of psychological well-being and perceived social support in England. J. R. Stat. Soc. Ser. A (Stat. Soc.) 2005, 168, 513-537. [CrossRef]

56. Diener, E.; Oishi, S. The nonobvious social psychology of happiness. Psychol. Inquiry 2005, 16, $162-167$. [CrossRef]

57. Kong, F.; You, X. Loneliness and self-esteem as mediators between social support and life satisfaction in late adolescence. Soc. Indic. Res. 2013, 110, 271-279. [CrossRef]

58. Matsuda, T.; Tsuda, A.; Kim, E.; Deng, K. Association between perceived social support and subjective well-being among Japanese, Chinese, and Korean college students. Psychology 2014, 5, 491. [CrossRef]

59. McIntyre, C.W.; Watson, D.; Cunningham, A.C. The effects of social interaction, exercise, and test stress on positive and negative affect. Bull. Psychon. Soc. 1990, 28, 141-143. [CrossRef]

60. Gallagher, E.N.; Vella-Brodrick, D.A. Social support and emotional intelligence as predictors of subjective well-being. Personal. Indiv. Differ. 2008, 44, 1551-1561. [CrossRef]

61. Brannan, D.; Biswas-Diener, R.; Mohr, C.D.; Mortazavi, S.; Stein, N. Friends and family: A cross-cultural investigation of social support and subjective well-being among college students. J. Posit. Psychol. 2013, 8, 65-75. [CrossRef]

62. Scholz, U.; Kliegel, M.; Luszczynska, A.; Knoll, N. Associations between received social support and positive and negative affect: Evidence for age differences from a daily-diary study. Eur. J. Ageing 2012, 9, 361-371. [CrossRef] [PubMed]

63. Green, M.; DeCourville, N.; Sadava, S. Positive affect, negative affect, stress, and social support as mediators of the forgiveness-health relationship. J. Soc. Psychol. 2012, 152, 288-307. [CrossRef] [PubMed]

64. Kong, F.; Zhao, J.; You, X. Self-esteem as mediator and moderator of the relationship between social support and subjective well-being among Chinese university students. Soc. Indic. Res. 2013, 112, 151-161. [CrossRef]

65. Yanning, Z.; Feng, K. Relationship between Social Support, Emotional Intelligence and Subjective Well-being in Adults. China J. Health Psychol. 2012, 20, 50-51.

66. Greenglass, E.R.; Fiksenbaum, L. Proactive coping, positive affect, and well-being: Testing for mediation using path analysis. Eur. Psychol. 2009, 14, 29-39. [CrossRef]

67. Diener, E. Subjective well-being. Psychol. Bull. 1984, 95, 542-575. [CrossRef] [PubMed]

68. Diener, E. Subjective well-being: The science of happiness and a proposal for a national index. Am. Psychol. 2000, 55, 34-43. [CrossRef] [PubMed]

69. Stutzer, A.; Frey, B.S. Recent advances in the economics of individual subjective well-being. Soc. Res. 2010, 77, 679-714.

70. Chang, E.C.; Sanna, L.J. Optimism, pessimism, and positive and negative affectivity in middle-aged adults: A test of a cognitive-affective model of psychological adjustment. Psychol. Aging 2001, 16, 524-531. [CrossRef] [PubMed]

71. Chang, E.C.; Sanna, L.J.; Yang, K.-M. Optimism, pessimism, affectivity, and psychological adjustment in US and Korea: A test of a mediation model. Personal. Indiv. Differ. 2003, 34, 1195-1208. [CrossRef]

72. Ya, L.; Zhen-hong, W.; Juan, M.; Jing-ping, H. Relations Between Extraversion and Satisfaction with Life:Chain Mediating Effect of Affect and Self-Esteem. Chin. J. Clin. Psychol. 2011, 19, 666-668.

73. Cohn, M.A.; Fredrickson, B.L.; Brown, S.L.; Mikels, J.A.; Conway, A.M. Happiness unpacked: Positive emotions increase life satisfaction by building resilience. Emotion 2009, 9, 361. [CrossRef] [PubMed]

74. Xiuhong, M.; Zhaohui, H.; Ying, S.; Fangbiao, T.; Yuhui, W.; Shaojun, X. Coping styles as mediators of associations among life satisfaction and depression/anxiety. J. Jilin Univ. Med. Ed. 2010, 36, 989-993.

75. Hongfang, Q.; Tingji, P. Dispositional Optimism and Life Satisfaction of Chinese and Japanese College Students: Examining the Mediating Effects of Affects and Coping Efficacy. Chin. J. Clin. Psychol. 2011, 19, 259-261.

76. Dan, H.; Fang, Y. Relationship among Core Self-evaluations, Positive Affect and Life Satisfaction of Adolescences. China J. Health Psychol. 2013, 21, 891-892.

77. Liu, Y.; Wang, Z.; Lü, W. Resilience and affect balance as mediators between trait emotional intelligence and life satisfaction. Personal. Indiv. Differ. 2013, 54, 850-855. [CrossRef]

78. Yip, W.; Subramanian, S.; Mitchell, A.D.; Lee, D.T.; Wang, J.; Kawachi, I. Does social capital enhance health and well-being? Evidence from rural China. Soc. Sci. Med. 2007, 64, 35-49. [CrossRef] [PubMed]

79. Yong, G.; Guirong, H. Measuring Community Social Capital: An empirical study. Sociol. Stud. 2008, 3, 122-142. 
80. Diener, E.; Suh, E.M.; Smith, H.; Shao, L. National differences in reported subjective well-being: Why do they occur? Soc. Indic. Res. 1995, 34, 7-32. [CrossRef]

81. Watson, D.; Clark, L.A.; Tellegen, A. Development and validation of brief measures of positive and negative affect: The PANAS scales. J. Personal. Soc. Psychol. 1988, 54, 1063-1070. [CrossRef]

82. Fredrickson, B.L.; Cohn, M.A.; Coffey, K.A.; Pek, J.; Finkel, S.M. Open hearts build lives: Positive emotions, induced through loving-kindness meditation, build consequential personal resources. J. Personal. Soc. Psychol. 2008, 95, 1045-1062. [CrossRef] [PubMed]

(C) 2018 by the authors. Licensee MDPI, Basel, Switzerland. This article is an open access article distributed under the terms and conditions of the Creative Commons Attribution (CC BY) license (http://creativecommons.org/licenses/by/4.0/). 